\title{
EDUCAÇÃO AMBIENTAL A PARTIR DA AGENDA 2030: EXPERIÊNCIAS DA CONSCIENTIZAÇÃO E DO USO RACIONAL DA ÁGUẢ EM UMA ESCOLA MUNICIPAL DE VARGINHA (MG)
}

\author{
Donizeti Leão de Miranda ${ }^{1}$ \\ Alexandre Tourino Mendonça² \\ Marília Carvalho de Melo $^{3}$ \\ Elisa Dias de Melo ${ }^{4}$
}

Resumo: A realidade dos recursos hídricos (da água) é impactada pelo grande desperdício e pela falta de preservação. Enfatizar novas práticas de gestão e Educação Ambiental para o consumo consciente e redução de desperdício da água se fazem emergentes para toda a sociedade, inclusive as ações propostas para crianças pequenas em âmbito escolar. Desta feita, avaliar o resultado da introdução de um projeto investigativo, subsidiado na Agenda 2030 e em seus Objetivos do Desenvolvimento Sustentável (ODS 4, meta 4.7 e ODS 6), em relação à conscientização e uso racional da água na Escola Municipal Professora Maria Aparecida de Abreu de Varginha-MG se fez objetivo deste artigo.

Palavras-chave: Água; Educação Ambiental; Agenda 2030.

Abstract: The reality of water resources has affected by great waste and lack of preservation. Emphasizing new management practices and environmental education for conscious consumption and reduction of water waste are emerging for the whole of society, and the actions proposed for young children in school are included. Evaluate the result of the introduction of an investigative project, subsidized in the Agenda 2030 and in its Sustainable Development Goals (ODS 4, goal 4.7 and ODS 6), in relation to the awareness and rational use of water at the Maria Aparecida de Abreu, a Municipal School in VarginhaMG, was the objective of this article.

Keywords: Water; Environmental Education; Agenda 2030.

\footnotetext{
1 Universidade Vale do Rio Verde - Unincor. E-mail: eng.leao@leaoconsultoria.com. 2 Universidade Vale do Rio Verde - Unincor.. E-mail: alexandre.tourino@unincor.edu.br. 3 Universidade Vale do Rio Verde - Unincor. E-mail: prof.marilia.melo@unincor.edu.br 4 Universidade Vale do Rio Verde - Unincor. E-mail: prof.elisa.melo@unincor.edu.br
}

Revbea, São Paulo, V. 16, № 2: 174-190, 2021. 


\section{Introdução}

A presença do ser humano no planeta, influenciou o equilíbrio do meio ambiente, a medida em que passou a explorar a natureza para abrigar-se ou para alimentar-se. Contudo, o atendimento às necessidades foi cedendo lugar para o neoliberalismo, o consumo compulsivo e o capitalismo e, com isso, os problemas ambientais são resultantes da trajetória do desenvolvimento dos homens.

Especificamente, em relação aos recursos hídricos (a água), sabe-se que sua realidade é impactada pelo grande desperdício, pela falta de preservação e por sua má gestão ambiental. Muitas políticas públicas ambientais - como por exemplo, as políticas florestais e de reservas legais foram propostas tardiamente, com vistas a socorrer o grande problema causado. Entretanto, muitos danos causados ao meio ambiente não são passíveis de reparos, não restando ao ser humano a preservação do que, ainda, existe. Ousa-se afirmar que não resta, ao ser humano, outra alternativa, senão a de educar-se para continuar a viver.

A demanda por educação para a vida é subsidiada por leis voltadas à proteção do ambiente (o funcionamento do Direito Ambiental) e regulamentação de seus sistemas - como por exemplo, a Agenda 2030 para o Desenvolvimento Sustentável e seus Objetivos do Desenvolvimento Sustável (ODS). Assim, a questão ambiental vem sendo pauta mundial e a referida Agenda, funcionando como Educação Ambiental (EA), inclusive para que a proposição de consumo consciente e redução do desperdício da água (ODS 6) possa ocorrer e se cumprirem por meio de propostas educativas (ODS 4, meta 4.7). A EA passou a ser trabalhada no contexto escolar por meio de projetos, enquanto proposta pedagógica embasada em diretrizes da educação e metodologias ativas do processo ensino-aprendizagem.

Segundo Moreira (2019), o Brasil detém aproximadamente 12\% da água doce total do planeta, o que vem criando uma falsa ilusão de estabilidade de água boa e disponível. O fato é que o país não está, e nunca esteve, livre de crises hídricas. Estas se relacionam aos processos de distribuição e de conhecimento (gestão) de recursos, e não somente relacionada à escassez. Por esta assertiva, devem ser enaltecidos os princípios ambientais como condutas éticas na tomada de decisões relativas ao uso racional e consciente da água, inclusive na educação.

Por todas as considerações prévias, busca-se, por meio da promoção da EA na educação de crianças pequenas, a desenvoltura de projetos de conscientização para preservação do uso da água. Desta feita, encontra-se na Secretaria de Educação Municipal de Varginha-MG junto à Escola Municipal Professora Maria Aparecida de Abreu, a parceria para proposição de projetos. A instituição de educação em questão já participa de iniciativas e projetos municipais e estaduais afins, como por exemplo, o Projeto Cultivando Água Boa e Programa Chuá, com ações centradas nos ODS 4.7 e 6 da Agenda 2030.

Revista brasileira educação ambiental 
O objetivo geral é implantar e avaliar o resultado da introdução de um novo programa/projeto de EA, subsidiado na Agenda 2030, em relação à conscientização e uso racional da água na Escola Municipal Professora Maria Aparecida de Abreu de Varginha-MG. Os objetivos específicos se elencam em: conhecer as ações da educação municipal (por meio de sua Secretaria de Educação) em relação à EA e a conscientização e uso racional da água; relatar experiências exitosas da EA, em relação ao Projeto da Agenda 2030 (e seus ODS 6 e 4.7) junto à escola em estudo, aos discentes e à sua comunidade local e; a partir dos resultados obtidos, elaborar uma cartilha educativa.

Políticas púbicas ou ações educativas que se referem ao uso racional da água mantém seu foco no aumento da produção da água, sendo escassas aquelas voltadas para a diminuição do consumo e do desperdício. Para mudança deste contexto, ações de conscientização de que a água é um recurso finito são necessárias, e com emergência (SILVEIRA et al., 2015) como aquelas propostas já descritas, anteriormente, como objetivos.

Assim, a EA deve buscar estabelecimento de relações em sintonia entre os homens e a natureza e, de acordo com Silva (2019), pode ser colocada em prática por meio das competências, sendo definidas como mobilizações de conhecimentos, habilidades, atitudes e valores que se destinam às resoluções de demandas rotineiras/cotidianas, para exercitarem a cidadania e problemas relacionados ao mundo contemporâneo.

Portanto, pela demanda em relação à preservação ambiental dos recursos hídricos (por meio do uso racional e consciente da água) e para o cumprimento da Agenda 2030 (e seus ODS 6 e 4.7), no âmbito educacional, a realização do projeto proposto, com a culminância de elaboração de uma cartilha educativa, encontra sua relevância e se justifica.

\section{Revisão de literatura}

\section{Crise hídrica e uso racional e consciente da água}

A escassez ou falta da água é elemento presente na equação da crise hídrica, e vem acontecendo gradativamente desde 2012, com a contribuição significativa da ação do homem. Especialistas alertam que a mudança emergente de comportamento é o que poderá garantir o não agravamento da situação, frente ao seu uso inadequado do recurso (BRITO, 2018).

A Agência Nacional de Águas (ANA, 2019), afirma que a escassez da água é uma soma de dois fatores: a distribuição inadequada associada ao uso inadequado da água das nascentes pela grande concentração de propriedades em suas proximidades. Afirma que o uso exacerbado da água precisa ceder lugar para o uso racional e o consumo consciente, por meio de reeducação de hábitos simples, a começar pelas torneiras e chuveiros abertos constantemente, sem necessidade. Assim, um fator determinante para a conjuntura vem sendo o desperdício. Para preservar a água, não se faz necessário ficar sem o recurso, mas usá-lo sem desperdício, pois é uma 
prioridade ambiental e social, e sua falta é prejudicial para manutenção da vida saudável.

Ainda, a referida agência alerta que sejam necessárias campanhas de incentivo do uso racional e consciente, pois esta forma de uso vem representar economia doméstica, economia com esgotos e evitar degradação ambiental. Propõe pequenos cuidados que minimizem tanto o desperdício, quanto as contas de água das residências e localidades, dependendo somente de boas iniciativas, mudanças comportamentais, reeducação e renovação de atitudes (ANA, 2019).

A gestão dos recursos hídricos deve educar e ajustar atividades humanas para a precaução de degradação do ecossistema e para a preservação do meio, ocorrendo por meio de ações que envolvam o governo e a sociedade. Só se concretiza como eficiente e viável ao passo que norteada pela EA, acreditando que a consciência é o ponto de partida da população, da mesma forma que norma reguladora daqueles que tomam decisões que envolvem a exploração do meio ambiente (e seus recursos naturais) e a promoção de seu equilíbrio (CHACON-PEREIRA et al., 2018).

O uso racional e consciente da água objetiva o controle (quantitativo e qualitativo) seguro, para a promoção e garantia do direito igualitário do seu uso, bem como cumprimento dos princípios ambientais envolvidos, sendo eles: exploração, conservação e preservação (RIBEIRO, 2018).

\section{A Agenda 2030 e seus Objetivos do Desenvolvimento Sustentável}

A Agenda 2030, vem corresponder a uma adversidade de programas/ações/diretrizes reunidas para orientar o trabalho da Organização das Nações Unidas (ONU) e de seus países membros rumo ao desenvolvimento sustentável. Formou-se a partir de ações negociadas, culminado em agosto de 2015, em consenso pelos seus Estados-membros, e edificadas por meio da proposta de 17 Objetivos do Desenvolvimento Sustentável (ODS) e 169 metas correspondentes (BRASIL, 2018).

Junto aos ODS, considerados como o centro da proposta, a Agenda propõe colocar o mundo em um sentido sustentável, acreditando na necessidade de ações transformadoras e ousadas. Suas metas têm o potencial de representar uma mudança em direção à sustentabilidade e a uma realidade social mais justa e inclusiva. Nesse diapasão, a educação é um elementochave para se atingir os referidos objetivos sustentáveis (RODRIGUES, 2019).

O ODS 4 e sua meta 4.7 vêm conquistando espaço nas escolas, a justificar-se em sua característica sócio-política, enxergando a escola (a educação) como um campo propício para experiências inovadoras e exitosas, com vistas a uma sociedade mais sustentável; enxergando a escola (a educação) enquanto garantia do envolvimento da comunidade em questões que envolvam discussões de diversidade e propostas de solução para um mundo mais democrático e sustentável. Consideram a sustentabilidade como 
uma questão de atitude resultante de mudanças de comportamentos, nos processos de produção e consumo e, tais mudanças, são atingidas pela educação (RODRIGUES, 2019).

De acordo com o Programa das Nações Unidas para o Desenvolvimento (PNUD, 2018), a educação é o elemento fundamental que a humanidade atinja os almejados ODS. Através de sua meta 4.7 é possível oportunizar o desenvolvimento sustentável (como, por exemplo, da água), com a promoção de ações educativas e educadoras. É possível desenvolver a proposta do ODS 6 , garantindo que todos os alunos (crianças) estejam envolvidos, educados e conscientizados numa proposta sustentável, oportunizando melhorias ambientais que possam favorecer a qualidade de vida na família, na comunidade, na sociedade e no planeta, principalmente em relação ao uso racional e sustentável da água.

\section{A Educação Ambiental}

Gomes e Mendes (2012) afirmam que a EA deve estar orientada para a sociedade, envolvendo indivíduos de forma ativa nas resoluções de problemas de contextos específicos, além de incentivar a responsabilidade e sensibilizar para o empenho na construção de um futuro melhor. Para Rodrigues (2019), é compreendida como toda e qualquer ação educativa que passe a contribuir para a formação de um cidadão mais consciente em relação à preservação do meio ambiente.

A EA se faz uma das vertentes do processo global educacional, destinada a todos os sujeitos inseridos em sociedade. Especialmente, para crianças pequenas, deve ser procedida mediante um processo metodológicopedagógico participativo, de modo permanente, com inserção de visão crítica, de despertar de consciência e motivação de habilidades para solução dos problemas emergentes (REIGADA; REIS, 2004).

Se faz necessário, ainda, um processo educativo que visa formar cidadãos éticos nas suas relações com a sociedade e com a natureza. Neste contexto, a escola surge como um importante agente socializador, uma vez que é responsável não apenas pela difusão de conhecimentos, mas pela transmissão dos valores entre diferentes gerações (REIGADA; REIS, 2004).

Trajber e Sato (2010) definem a escola como um espaço educador (ou educativo) sustentável intencionado, pedagogicamente, para contribuições de referências em questões sustentáveis e de sustentabilidade social e ambiental; um espaço capaz de sustentar e manter relações equilibradas junto ao meio ambiente e, acima de tudo, um espaço participativo.

Médis (2016) acredita que, dentro do processo metodológico-pedagógico participativo, a EA pode concretizar sua proposta sustentável coletiva por meio da elaboração de cartilhas, construídas nos espaços escolares, destinados à comunidade local. Para Chacon-Pereira et al. (2018), na conjuntura, os recursos hídricos apresentam-se como um tema relevante, que se influencia 
pela interação cultural, demandando por um processo de alfabetização ambiental relacionado à água, precisando ultrapassar os limites do conhecimento de ciências (conhecimento disciplinar de química e ecologia) podendo se cumprir por meio de edificação e distribuição de cartilhas.

\section{Cartilhas educativas (para a promoção do uso racional e consciente da água)}

As cartilhas de cunho ambiental promovem um discurso persuasivo, pois dirigem-se diretamente aos seus leitores, falando a um e a todos ao mesmo tempo. Em seu sentido didático, convidam os sujeitos à participação da construção de um mundo melhor. Consideram-se como objetos discursivos, a partir de uma produção apropriada de uma conjuntura sócio histórica particular junto aos sujeitos interessados pelo conhecimento que passam a produzir (MÉDIS, 2016).

Nas cartilhas educativas de cunho ambiental sempre existe uma tentativa de aproximação por meio de uso de recursos gráficos e midiáticos que permitam a pedagogização das informações. Sempre existe uma proposta de metodologia ativa do processo de ensino-aprendizagem; do processo de educação (GOMES; MENDES, 2012).

Para Medis (2016), neste processo de pedagogização, apoiado nas metodologias ativas, existe a questão da circularidade uma caracterização do discurso de ensinar ou de educar, muito mais forte do que a caracterização de demais discursos, com por exemplo, de informar, persuadir ou influenciar. Além disso, está presente a democratização dos saberes (a todos da escola e à sua comunidade) como uma forma de educar. Para Rodrigues (2019), outra caracterização da circularidade do discurso está na cientificidade das informações a serem transmitidas - o que promove características de um discurso pedagógico.

Toda cartilha de cunho ambiental, em sua materialidade, constitui-se uma pedagogização que trabalha a formação (comportamental) do cidadão em um processo contínuo de aperfeiçoamento do conhecimento (no caso, ambiental) (MÉDIS, 2016). Assim, por meio de cartilhas pedagógicas educativas (ODS 4, meta 4.7) podem ser produzidas respostas às demandas da sociedade e do meio ambiente, por meio de instrumentos e tecnologias, que passam a legislar a matéria a saber (ODS 6), com vistas à conformação, a adaptação e a reprodução de comportamentos ideais e de relações socioambientais.

\section{Procedimentos metodológicos}

Para o cumprimento dos objetivos propostos, optou-se por uma pesquisa aplicada do tipo exploratório-descritiva, cumprida por meio documental e de campo, com abordagem quali-quantitativa (GIL, 2008). 
A área de estudo foi o município de Varginha-MG e o objeto foi a educação em sua esfera municipal, sendo realizada na Escola Municipal Professora Maria Aparecida Abreu enquanto unidade de estudo. Oferta Ensino Fundamental I (de $1^{\circ}$ ao $5^{\circ}$ ano) e Ensino Fundamental II (de $8^{\circ}$ ao $9^{\circ}$ ano) em tempo integral. Os abastecimentos de água e energia são realizados pela rede pública. O destino do esgoto é fossa, e o destino do lixo é coleta periódica (PREFEITURA MUNICIPAL DE VARGINHA, 2020).

A população de pesquisa para a coleta de dados foi formada: pela Secretaria de Educação do Município (SEDUC); pela Administração da Escola Municipal Professora Maria Aparecida de Abreu; pela docência do Ensino Fundamental I (de $1^{\circ}$ ao $5^{\circ}$ ano); por 100 crianças/discentes desta modalidade de ensino e; pela sua comunidade local, representada por 6 pais/lares das referidas crianças.

Os procedimentos e instrumentos de pesquisa (coleta de dados) foram: palestras educativas, junto às crianças/discentes e à comunidade local, utilizando-se de conteúdo didático preparado; entrevistas com a SEDUC do Município e junto à coordenação da escola em estudo, aplicação de questionários qualitativos e; visitas realizadas às margens do Rio Verde, à uma Mini Estação de Tratamento de Água (ETA) de um clube localizado às margens do referido rio, bem como à Mina D'Água da cidade. Para todos esses eventos foram coletadas fontes de evidências, que se resumem em produções textuais e desenhos produzidos pelas crianças envolvidas no estudo. Tais registros de evidências e achados com os questionários aplicados fizeram parte da análise qualitativa dos dados, recorrendo-se à análise de conteúdo.

Além disso, foram utilizadas contas de águas da escola em estudo, bem como da comunidade local - um total de 6 pais/lares voluntários. Para tanto, uma análise quantitativa foi promovida, contemplando uma apuração estatística simples, com vistas à aferição das contas de água, para verificar se no período do referido projeto de EA houve conscientização e uso racional da água.

\section{Resultados e discussão}

\section{Ações da SEDUC de Varginha (MG) para a Educação Ambiental, conscientização e uso racional da água}

A EA promovida para o uso racional da água (preservação dos recursos hídricos) e para preservação de outros recursos naturais junto às escolas, pela SEDUC, objetiva a formação de pequenos cidadãos para um meio ambiente mais sustentável, com acesso à igualdade de oportunidades, envolvendo toda a sua comunidade e a sociedade local, garantindo o direito do exercício da cidadania e do conhecimento democrático diante de soluções para os problemas ambientais.

Costa, Lopes Junior e Silva (2018), em uma proposta semelhante de EA para crianças pequenas, cujo foco foi a gestão dos recursos hídricos, afirmaram que o sucesso da promoção deste tipo de iniciativa educacional é 
justamente o envolvimento de todos os sujeitos inseridos no contexto, lançando mão de ações diversificadas, para que um número grande de pessoas possa ser atingido simultaneamente. Afirmaram que a participação da população junto à comunidade escolar só faz aumentar o senso crítico e, consequentemente, diminuir conflitos existentes que impeçam que a preservação e manutenção dos recursos naturais se efetivem.

Almeida et al. (2019) advogam pela necessidade da escola buscar, pedagogicamente, a inserção de projetos que visem a conscientização sobre a necessidade do uso racional da água em todos os setores da sociedade. Advogam que as propostas estejam além dos muros das escolas, compreendendo demais setores e profissionais engajados, a comunidade local e todos aqueles que necessitam do sendo de responsabilidade ambiental coletiva.

\section{O trabalho com o ODS 6 da Agenda 2030 na Escola Municipal Professora Maria Aparecida de Abreu}

A Escola Municipal Professora Maria Aparecida de Abreu se constitui um espaço social ideal para a conscientização do uso consciente e racional da água, por meio de vários projetos de consumo consciente e correta gestão dos recursos hídricos. A escola é inscrita em dois outros programas realizados pela Companhia de Saneamento de Minas Gerais (COPASA) junto às escolas municipais: o Programa Cultivando Água Boa (CAB) e o Programa Chuá.

Oliveira, Machado e Oliveira (2015) afirmam que a escola é um espaço para a abordagem da EA, justamente pelas oportunidades de atividades oferecidas em detrimento às mudanças comportamentais dos sujeitos que nela se encontram inseridos. Especificamente, em relação à educação dispensada à gestão dos recursos hídricos, os estudiosos acreditam que sua abordagem deva ser diária, mediante práticas exaustivas e possibilidades de atividades que motivem tais práticas e atitudes, sendo por meio destas possibilidades de comprobatórios de efeitos e causas.

\section{A descrição das experiências do trabalho com os ODS 6 e 4.7 da Agenda 2030 na Escola Municipal Professora Maria Aparecida de Abreu}

As experiências exitosas aconteceram mediante: palestras com docentes e discentes; palestras com a comunidade local (pais de discentes) e; visitações realizadas à margem do Rio Verde, à uma ETA no Clube Campestre de Varginha-MG e à Mina D’Água no bairro Campos Elísios. Taques et al. (2019) tais iniciativas como educação em ambientes não-formais.

Para as palestras, utilizou-se um conteúdo (em Power Point) preparado em momentos sequenciais: motivação, conscientização, sensibilização, interação e avaliação. Além disso, de forma didática, o conteúdo foi estruturado a partir de: imagens, vídeos, música, charges, brincadeiras e histórias em quadrinhos.

Revista brasileira educação ambiental 
Registra-se que o conteúdo/material utilizado com os discentes foi o mesmo que o utilizado com a comunidade escolar; contudo, para esta segunda clientela, além da questão da sustentabilidade, preservação e Educação Ambiental, alertou-se para promoção de uma economia direcionada (redução do uso do volume de água e redução da despesa com a conta de água) - uma forma de educação financeira e educação orçamentária.

A iniciativa de palestras com docentes, discentes e comunidade local (pais de discentes), em seu objetivo de promoção da Educação Ambiental, vem de encontro com as ponderações de Almeida et al. (2019), que defendem a ideia de uma abordagem específica a partir do lugar que em que vive para a possível construção de um espaço sustentável. Os autores reintegram a necessidade de uma abordagem ambiental educativa, entendendo que a escola e a comunidade local constituem tal sociedade sustentável, sendo instrumentos de visão holística para causas como o desperdício de água e o destino inadequado de resíduos, por exemplo.

A visita às margens do Rio Verde, na llha Grande dentro do Clube Campestre, foi um momento de conscientização espontânea para com a preservação das nascentes e mananciais. Na sequência, a visita à ETA do referido clube veio mostrar que este retira a água do próprio rio para tratamento e uso local. Foi uma explanação proveitosa, pois o processo da estação do clube é o mesmo que o da companhia de saneamento local que abastece o município com água tratada. Observou-se que o processo é longo, evolve muitos recursos e uso de materiais diversos. Muitos alunos questionaram as explicações, podendo sanar dúvidas e curiosidades e participar ativamente do aprendizado.

André, Macedo e Estender (2015), em projetos de EA e conscientização sobre destino de resíduos e desperdício de água, salientam a necessidade da vivência dos alunos em processos de tratamento apropriado para a água que consomem. Almeida et al. (2019) acreditam que vivências e experimentações são essenciais para promoção da Educação Ambiental, permitindo que as crianças façam parte do processo de gestão ambiental. A partir de tais experimentos é possível que elas articulem com mais facilidades as ações sociais em determinados espaços com vistas à garantida dos princípios e normas do direito ambiental, para garantia da sustentabilidade e da efetividade do processo educativo.

Por fim, encerrando a maratona de visitações, prosseguiu-se para a Mina D’Água, no bairro Campos Elísios. A mina é visitada por muitas pessoas do município de Varginha (MG )que, diariamente, buscam água limpa e natural para o consumo em seus lares. Todas as crianças tiveram a oportunidade de experimentar a água. Além disso, no momento de chegada ao local, as crianças foram alertadas a respeito da condição de limpeza e conservação do espaço.

Aproveitando tal cultura, bem como o espaço de aprendizado nãoformal, programou-se um lanche coletivo para finalizar a visitação. Cada 
criança levou um lanche coletivo para dividir com os colegas em um momento de confraternização de experiências exitosas com a Educação Ambiental. Após o lanche, outra iniciativa de EA foi proposta: a limpeza e conservação do local, deixando-o da mesma forma que foi encontrado no momento da chegada.

Esta ação de limpeza e conservação do entorno da mina faz parte da gestão do recurso hídrico, que segundo Costa, Lopes Junior e Silva (2018), não se resume em somente preservar um corpo hídrico, mas em preservar tudo aquilo que garante o seu sustento em uma escala global. Para os estudiosos, esta visão precisa ser reforçada nos projetos e programas de EA. Taques et al. (2019) afirmam que a aproximação de um processo ecológico ao aspecto social é o ponto de partida para a promoção de qualquer atividade educadora ambiental que objetive transformações de ações do homem sobre a natureza.

Com base no todo pesquisado e nas avaliações dos projetos exitosos em execução na Escola Municipal Professora Maria Aparecida de Abreu de Varginha-MG, aproveitando suas fontes de evidências (desenhos, histórias em quadrinho, de frases de efeitos e slogans sobre campanhas do uso racional da água; de registros fotográficos; textos etc.), como exemplo mostrado pela Figura 1, o resultado final foi a elaboração/confecção da cartilha, a ser difundida na comunidade local - conforme a Figura 2, na sequência.

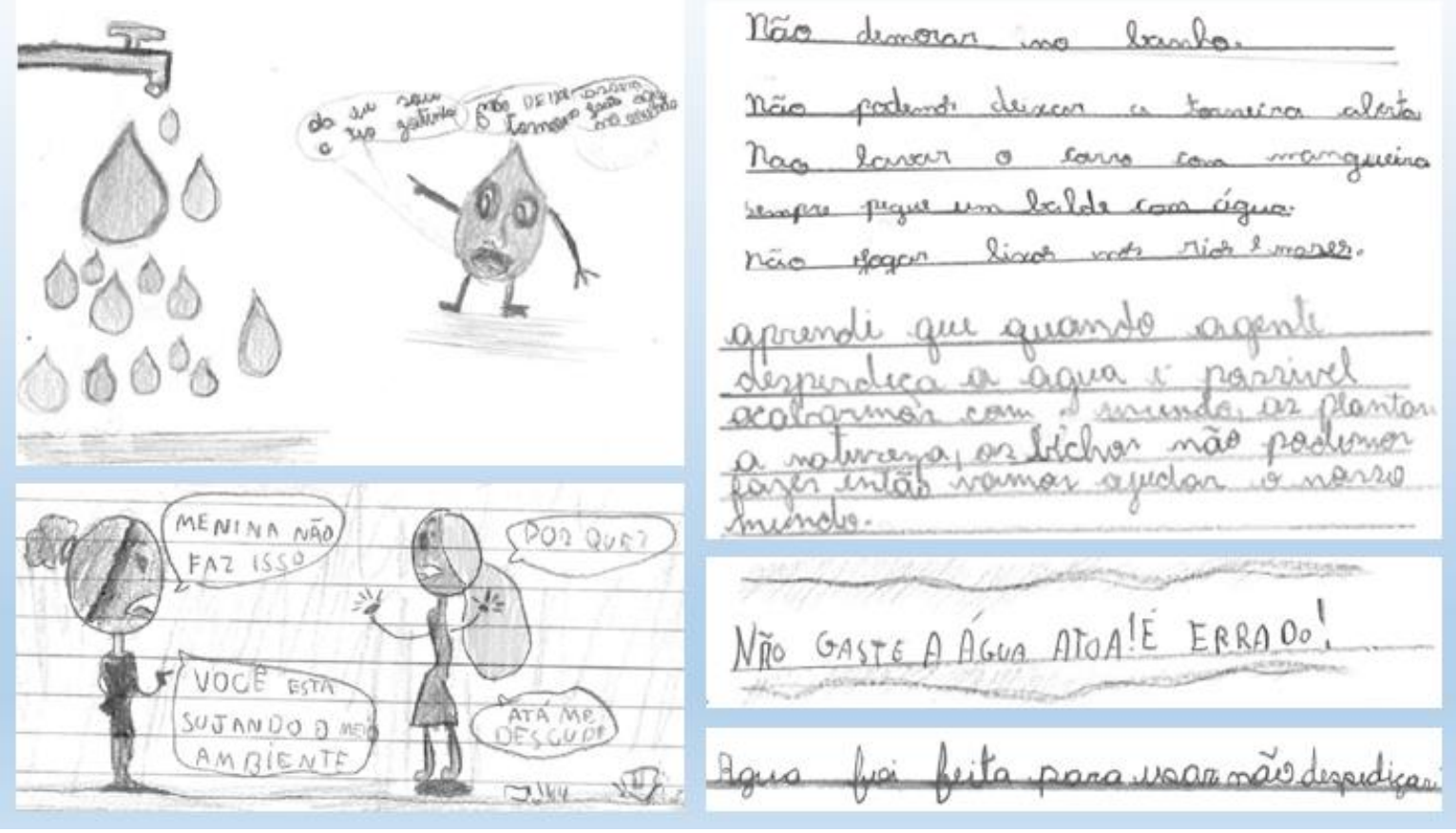

Figura 1: Fontes de evidência/resultados do projeto (mural).

Fonte: Dados da pesquisa (2019). 
Em ambas as evidências coletadas (organizadas em forma de mural, aqui), percebeu-se a consciência da existência ou ocasionalmente do dano ambiental, estando intimamente relacionado à responsabilidade civil (ou falta de), enquanto prejuízo causado a qualquer recurso ambiental natural indispensável para um ambiente equilibrado ecologicamente - 0 que possibilita espaço para a ação da Educação Ambiental.

Este resultado confirma os dizeres de Mendes, Mendes e Cristino (2018), de que a EA é uma forma de representação social, um ato político de busca pelas transformações sociais, entendidas enquanto processos permanentes de aprendizagem, que vem valorizando as diversas formas de produção de conhecimentos, voltadas para o exercício da cidadania, com pretensões às novas formas de encarar as relações entres os homens e a natureza, pressupondo valores morais e éticos.
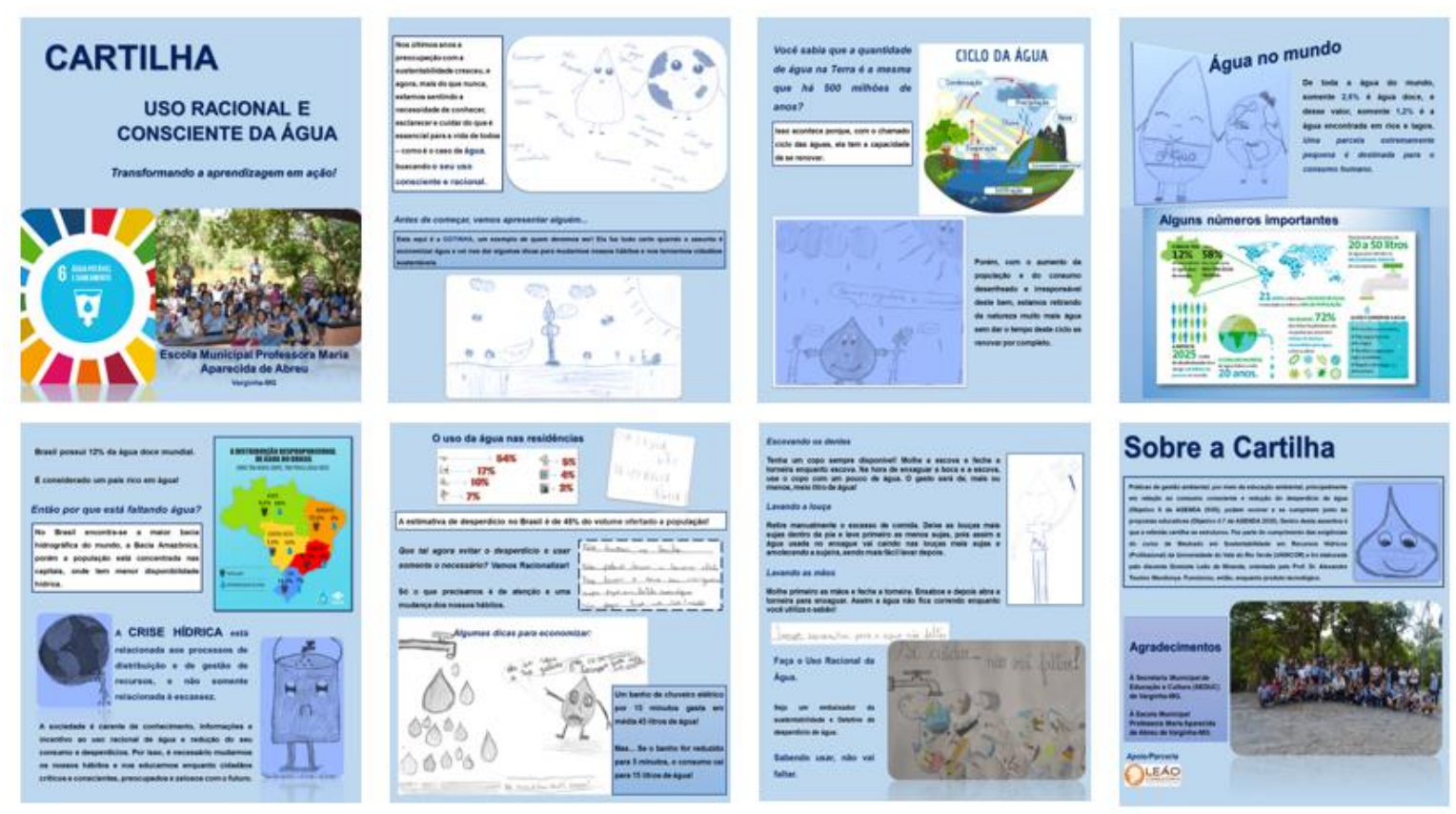

Figura 2: Cartilha do Uso Racional e Consciente da Água (mural).

Fonte: Dados da pesquisa (2019).

Por meio das evidências organizadas em forma de mural da referida cartilha (Figura 2), pode-se afirmar experiências exitosas do trabalho com os ODS 6 e 4.7 da Agenda 2030; pode-se afirmar a promoção da EA não resultou da simples prática de transmissão de conhecimentos, mas, da participação ativa dos envolvidos no projeto.

Castro e Carvalho (2012) alegam que o uso da cartilha construída pelos alunos na escola permite que estes abandonem a posição de receptores do conhecimento e assumam o papel de transmissores, verdadeiros protagonistas 
(do desenvolvimento sustentável) caracterizando-se como uma metodologia inovadora para a educação.

Para Médis (2016), a proliferação de cartilhas na sociedade, fora e dentro do espaço escolar, vem servindo para disseminar o conhecimento. Tal fato permite a afirmativa de que a cartilha educativa edificada, a partir das experiências exitosas na Escola Municipal Professora Maria Aparecida de Abreu e junto à sua comunidade, se constituiu a partir de sentidos de conhecimento científico de uma EA, para colocar em prática o desenvolvimento sustentável e o exercício da Educação Ambiental constante.

\section{Comprovação da promoção do uso racional e consciente da água em números}

Enquanto funcionamento empírico, a aplicação do projeto teve sua confirmação com a aferição de contas de água da escola em estudo, bem como das famílias/lares da sua comunidade que participaram voluntariamente da pesquisa. Assim, a Tabela 1 caracteriza a escola e a comunidade local participantes das aferições, segundo o número de pessoas consumidoras da água, de acordo com os dados informados pelos mesmos.

Tabela 1: Consumidores da água da COPASA

\begin{tabular}{l|l|l}
\hline Escola & $\begin{array}{l}\text { 470 discentes, 24 docentes, 6 estagiárias da docência, } \\
\text { 1diretora, 1coordenadora escolar, 6 colaboradoras para } \\
\text { serviços administrativos, 4 colaboradoras para auxílio de } \\
\text { limpeza e 2 para auxílio na cozinha/cantina. }\end{array}$ & Total: $\mathbf{5 1 4}$ pessoas \\
\hline Família $\boldsymbol{A}$ & 3 adultos e 1 criança & Total: $\mathbf{4}$ pessoas \\
\hline Família B & 2 adultos e 1 criança & Total: $\mathbf{3}$ pessoas \\
\hline Família $\boldsymbol{C}$ & 2 adultos e 3 crianças & Total: $\mathbf{5}$ pessoas \\
\hline Família $\boldsymbol{D}$ & 4 adultos e 3 crianças & Total: $\mathbf{7}$ pessoas \\
\hline Família $\boldsymbol{E}$ & 3 adultos e 3 crianças & Total: $\mathbf{6}$ pessoas \\
\hline Família $\boldsymbol{F}$ & 2 adultos e 2 crianças & Total: $\mathbf{4}$ pessoas \\
\hline
\end{tabular}

Fonte: Elaborado pelo autor, a partir dos dados coletados pela pesquisa (2019).

Registra-se que para a validação dos resultados, não foram reveladas as identidades das contas; mas, os números de leitura para média final/total sobre o consumo, objetivando revelar se os projetos em desenvolvimento sobre o uso racional da água promoveram efeitos positivos (ou não). Acrescenta-se que não foram levados em consideração os dias entre medições e a média diária ou mensal em litros de consumo nas referidas contas. O único dado relevante para a verificação do uso racional e consciente no histórico de consumo foi somente o volume faturado em litros - sendo este medido em metros cúbicos $\left(m^{3}\right)$.

Assim, as 6 famílias que concordaram em participar da aferição encarregaram-se de enviar, mensalmente, uma cópia/xerox da conta de água junto às crianças para a escola, recolhidas pelas docentes e coletadas como 
dados quantitativos, sendo as leituras lançadas em uma planilha para elaboração de gráficos como resultados.

Em uma visita às dependências da escola, constatou-se que a água consumida no local é fornecida pela COPASA e que não existem situações de irregularidades (tais como desperdício decorridos de vazamentos). Da mesma forma, foi questionado à comunidade participante acerca da existência de possíveis vazamentos de água em suas residências. Todas as 6 famílias participantes afirmaram inocorrências.

As Figuras 3 e 4, respectivamente, condensam os dados do consumo de água da Escola Municipal Professora Maria Aparecida de Abreu e do consumo das famílias da comunidade escolar voluntárias para o estudo.

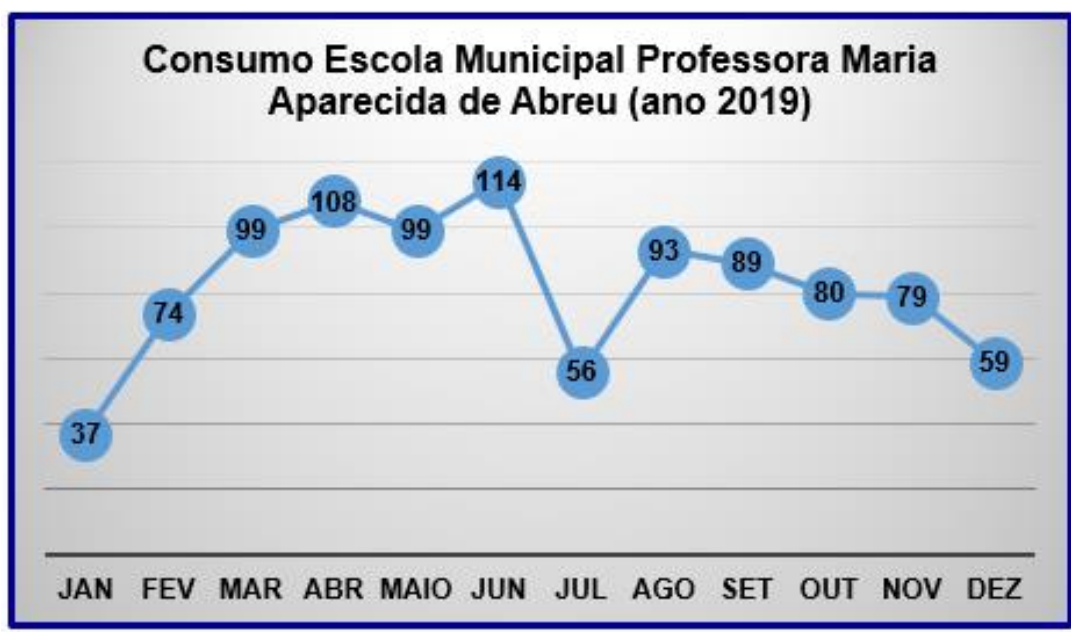

Figura 3: Consumo da Escola Municipal Professora Maria Aparecida de Abreu.

Fonte: Dados da pesquisa (2019).

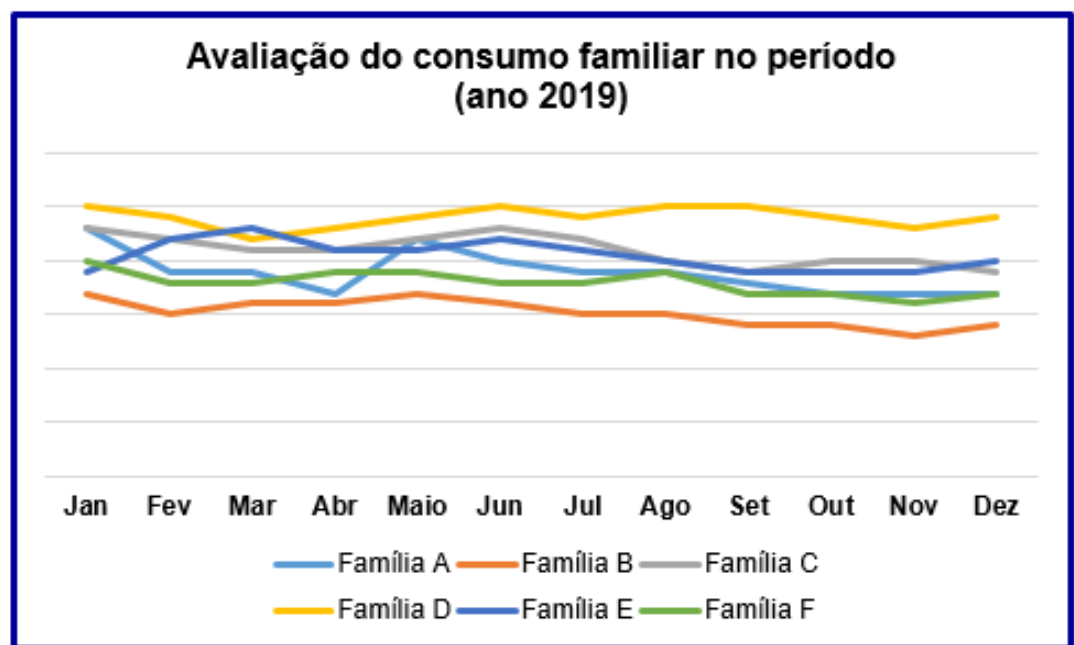

Figura 4: Avaliação do consumo familiar (comunidade) no período.

Fonte: Dados da pesquisa (2019). 
Faz-se necessário registrar que o projeto foi aplicado no período de agosto a dezembro do ano de 2019; entretanto, consideraram-se as aferições no período de janeiro a dezembro do mesmo ano, para facilitar a percepção do êxito (ou não) do projeto aplicado.

Retomando às análises, os dados da Figura 4 foram condensados, mas podem ser melhor compreendidos a partir da discriminação do consumo em $\mathrm{m}^{3}$ dos meses de aplciação do projeto na comunidade. Mediante tal organização, percebe-se a redução do consumo (em percentual). De acordo com o resultado, percebe-se que somente a Família $\mathrm{E}$ não apresentou resutlado positivo, em detrimento às demais famílias participantes (Tabela 2).

Tabela 2: Redução do consumo de água (\%) no período, a partir dos $\mathrm{m}^{3}$ mensais

\begin{tabular}{l|c|c|c|c|c|c}
\cline { 2 - 7 } & Ago. & Set. & Out. & Nov. & Dez. & $\begin{array}{c}\text { Redução de } \\
\text { Consumo }\end{array}$ \\
\hline Família $\boldsymbol{A}$ & 19 & 18 & 17 & 17 & 17 & $\mathbf{1 2 \%}$ \\
\hline Familia B & 15 & 14 & 14 & 13 & 14 & $\mathbf{7 \%}$ \\
\hline Família $\boldsymbol{C}$ & 20 & 19 & 20 & 20 & 19 & $\mathbf{5 \%}$ \\
\hline Família D & 25 & 25 & 24 & 23 & 24 & $\mathbf{4 \%}$ \\
\hline Família $\boldsymbol{E}$ & 20 & 19 & 19 & 19 & 20 & $\mathbf{0} \%$ \\
\hline Família $\boldsymbol{F}$ & 19 & 17 & 17 & 16 & 17 & $\mathbf{1 2 \%}$ \\
\hline
\end{tabular}

Fonte: Elaborado pelo autor, a partir dos dados coletados pela pesquisa (2019).

Assim, de acordo com os dados das Figuras 3 e 4 e da Tabela 2, podese afirmar que a Escola Municipal Professora Maria Aparecida de Abreu e sua comunidade local caminham para o desenvolvimento de uma consciência ambiental sustentável, perante indícios de um consumo mais consciente.

Kataoca et al. (2017) afirmam que o consumo consciente se encontra no estágio das dimensões sociais e culturais, que se esbarra nas mudanças de comportamento ou no processo de reeducação de atitudes e ações, que resulta em mudanças de posturas individuais que refletem no resultado coletivo para o controle do desperdício da água e a promoção de seu uso racional. Para tanto, simples discussões familiares são suficientes para revisão dos hábitos individuais e coletivos.

Feital et al. (2018) acreditam que a satisfação dos padrões de consumo vigentes vem envolvendo os homens em grandes desafios, sendo um deles a criação de uma sociedade econômica próspera, sustentável ecologicamente e socialmente justa acerca dos recursos naturais caracterizados como limitados. O consumo consciente não requer grandes mobilizações, mas se contenta em promover pequenas delas em diversas localidades fundamentais, sendo a escola e a família umas delas. Nesses dois âmbitos, a condução de um novo estilo de vida e de consumo pode ser efetivado, mediante orientações educativas e sustentáveis. 
Por meio da avaliação da proposta - ou seja, da promoção do cumprimento dos ODS 6 e 4.7 da Agenda 2030 - constatou-se um esforço em relação à mudança de comportamentos e atitudes dos sujeitos envolvidos em relação ao desperdício da água e promoção de seu uso racional e consciente, ficando provado por meio da análise das contas de água (da escola e da comunidade). Afirma-se, então, que o processo educativo promovido tenha sido exitoso, sendo contributivo com a comunidade local, a sociedade de forma geral e com o meio ambiente e planeta.

\section{Conclusões}

A Agenda 2030 e seus ODS vêm sendo instrumentos de construção de conhecimentos e saberes, propondo projetos investigativos para a escola, família e comunidade, permitindo reflexões permanentes sobre questões ambientais, na tentativa de promover minimização dos impactos e transformações ambientais, despertando a sensibilidade e a necessidade da educação e conscientização para a sustentabilidade.

Conclui-se que a melhor alternativa para a conscientização em relação ao uso consciente e racional da água seja a Educação Ambiental de crianças, enquanto embaixadoras da sustentabilidade e agentes de mudança, que pode acontecer no contexto da educação básica, a se cumprir nas propostas da Agenda 2030, principalmente por meio dos seus ODS 6 e 4.7 .

\section{Referências}

AGÊNCIA NACIONAL DAS ÁGUAS. Uso racional da água é a solução para a preservação desse recurso. 2019. Disponível em: $<$ https://www.ana.gov.br/noticias-antigas/uso-racional-da-a-gua-a-c-asoluassapso-para-a.2019-03-15.1643221791>. Acesso em: 6 jan. 2020.

ALMEIDA, N. C. C.; SANTOS JUNIOR, C. F.; NUNES, A.; LIZ, M. S. M. Educação Ambiental: a conscientização sobre o destino de resíduos sólidos, o desperdício de água e o de alimentos no município de Cametá/PA. Rev. Bras. Estud. Pedagog., v.100, n.255, mai./ago. 2019

ANDRÉ, D. S.; MACEDO, D.; ESTENDER, A. C. Conservação e Uso Racional da Água: Novos hábitos para evitar a escassez dos recursos hídricos e para a continuidade do bem finito. Anais do XII SEGET, out. 2015.

BRASIL. Ministério das Relações Exteriores. Agenda 2030 para o Desenvolvimento Sustentável. 2018. Disponível em: $<$ http://www.itamaraty.gov.br/pt-BR/politica-externa/desenvolvimentosustentavel-e-meio-ambiente/135-agenda-de-desenvolvimento-pos-2015>. Acesso em: 19 jan. 2019. 
BRITO, D. A água no Brasil: da abundância à escassez. Agência Brasil, 25 out. 2018. Disponível em: <http://agenciabrasil.ebc.com.br/geral/noticia/201810/agua-no-brasil-da-abundancia-escassez>. Acesso em: 10 jan. 2020.

CASTRO, A. D.; CARVALHO, A. M. P. Ensinar a ensinar: didática para a Escola Fundamental e Média. São Paulo: Cengage Learning, 2012.

CHACON-PEREIRA, A.; BATALHÃO, A. C. S.; SILVA, L. P.; NEFFA, E. Educação Ambiental na gestão de recursos hídricos baseada no modelo de licenciamento ambiental. Desenvolv. Meio Ambiente, v. 49, n. 1, p. 36-59, dez. 2018.

COSTA, N. B.; LOPES JUNIOR, J. M. SILVA, F. B. Recursos hídricos e Educação Ambiental: uma síntese bibliográfica. Anais do $\mathrm{V}$ Congresso Nacional de Educação, 2018. Disponível em: $<$ http://www.editorarealize.com.br/revistas/conedu/trabalhos/TRABALHO EV11 7 MD4 SA14 ID1402 10092018212904.pdf>. Acesso em: 17 dez. 2019.

FEITAL, J. C. C.; SPERS, E. E.; NETTO, A. F. N.; SPERS, V. R.; PONCHIO, M. C. O Consumo consciente da água: um estudo do comportamento do usuário doméstico. Anais do III ANPAD, Curitiba, maio. 2018. Disponível em: $<$ http://www.anpad.org.br/admin/pdf/EMA256.pdf>. Acesso em: 10 jan. 2020.

GIL, A. C. Como elaborar projetos de pesquisa. 4. ed. São Paulo: Atlas, 2008.

GOMES, R.; MENDES, A. B. Educação Ambiental à luz da análise dialógica do discurso: saber científico e quadrinização no gênero textual cartilha quadrinizada. Revista Estação Científica, Macapá, v.2, n.2, p. 65-78, jul./dez. 2012.

KATAOKA, A. M.; AFFONSO, A. L. S.; MOSER, A. S.; FISS, B. K.; MATAKAS, B. G. Reflexão sobre alternativas metodológicas para a inserção da Educação Ambiental crítica no ambiente escolar. Rev. Bras. Ens. Cie. Tecnol., Ponta Grossa, v. 10, n. 1, p. 1-17, 2017.

MÉDIS, K. R. Relações de Infância, Consumo e Sustentabilidade. 2016. 114 f. Dissertação (Mestrado). Pós-Graduação em Ciências da Linguagem da Universidade do Vale do Sapucaí, Pouso Alegre/MG.

MENDES, M. P.; MENDES, R. L. R.; CRISTINO, M. G. Meio ambiente e representação social. Rev. Eletrônica Mestr. Educ. Ambient. Rio Grande, v. 35, n. 2, p. 173-192, maio/ago. 2018.

MOREIRA, G. Dia Mundial da Água 2019 - 'Não deixar ninguém para trás'. Nações Unidas Brasil. Disponível em: <https://nacoesunidas.org/artigo-diamundial-da-agua-2019-nao-deixar-ninguem-para-tras/>. Acesso: 20 jan. 2019.

OLIVEIRA, J. T.; MACHADO, R. C. D.; OLIVEIRA, E. M. Educação Ambiental na escola: um caminho para aprimorar a percepção dos alunos quanto à importância dos recursos hídricos. Periódico Eletrônico Fórum Ambiental da Alta Paulista, São Paulo, v. 11, n. 4, p. 311-324, 2015. 
PREFEITURA DE VARGINHA. Varginha. 2020. Disponível em: <http://www.varginha.mg.gov.br/a-cidade>. Acesso em: 18 jan. 2020.

PROGRAMA DAS NAÇÕES UNIDAS PARA O DESENVOLVIMENTO. Plataforma agenda 2030: acelerando as transformações para a agenda 2030 no Brasil. 2018. Disponível em: $<$ https://acervodigital.ufpr.br/bitstream/handle/1884/58770/R\%20-\%20E\%20\%20GABRIEL\%20CHAVES\%20BARBOZA.pdf?sequence $=1$ \&isAllowed $=\mathrm{y}>$. Acesso em: 18 ago. 2018.

REIGADA, C.; REIS, M. F. C. T. Educação Ambiental para crianças no ambiente urbano: uma proposta de pesquisa-ação. Ciência e Educação, Bauru, n.2, p. 149-159, 2004.

RIBEIRO, W. A. O direito à água e saúde pública. Revista de Direito Sanitário, v. 18, n. 3, p. 94-103, 2018.

RODRIGUES, A. P. A Agenda 2030: transparência e opacidade dos/nos discursos para a globalização. 2019. 155f. Tese (Doutorado). Pós-Graduação em Ciências da Linguagem da Universidade do Vale do Sapucaí, Pouso Alegre/MG.

SILVA, D. S. Articulações entre Agenda 2030, Objetivos do Desenvolvimento Sustentável (ODS) e Base Nacional Comum Curricular (BNCCD). 2은 Congresso Internacional Media Ecology and Image Studies, 2019. Disponível em: $<$ http://meistudies.org/index.php/cmei/2cmei/paper/download/512/308 >. Acesso em: 10 jan. 2020.

SILVEIRA, A. P. G.; LIMA MELO, B.; OLIVEIRA MENDES, T.; BEZERRA, H. R. S.; RAMOS, G. C.; REIS, J. S.; SILVA, P. S. F. Educação Ambiental e consumo consciente da água. Anais do $55^{\circ}$ Congresso da Associação Brasileira de Química, Goiânia, nov. 2015. Disponível em: <http://www.abq.org.br/cbq/2015/trabalhos/5/8210-21535.html>. Acesso em: 10 jan. 2020.

TAQUES, R. C. V.; KATAOKA, A. M.; MARTINS, S. C. S.; STRUGAL, D. Práticas de Educação Ambiental em ambientes não formais de educação: um desafio no gerenciamento dos recursos hídricos. Revista Educação Ambiental em Ação, n. 69, set./nov. 2019.

TRAJBER, R; SATO, M. Escolas Sustentáveis: Incubadoras de Transformações nas Comunidades. Revista Eletrônica do Mestrado em Educação Ambiental, Rio Grande, v. 32, p.1-9, set. 2010. 